Chapman University

Chapman University Digital Commons

$11-9-2020$

\title{
Does a Good Advisor a Day Keep the Doctor Away? How Advisor- Advisee Relationships are Associated with Psychological and Physical Well-Being among Graduate Students
}

\author{
Monica Becerra \\ University of California, Irvine, becerrm1@uci.edu \\ Emily Wong \\ University of California, Los Angeles, emilyfwong@ucla.edu \\ Brooke N. Jenkins \\ Chapman University, bjenkins@chapman.edu \\ Sarah D. Pressman \\ University of California, Irvine, pressman@uci.edu
}

Follow this and additional works at: https://digitalcommons.chapman.edu/psychology_articles

Part of the Educational Methods Commons, Educational Psychology Commons, Higher Education Commons, and the Other Psychology Commons

\section{Recommended Citation}

Becerra, M., Wong, E., Jenkins, B.N., \& Pressman, S.D. (2020). Does a good advisor a day keep the doctor away? How advisor-advisee relationships are associated with psychological and physical well-being among graduate students. International Journal of Community Well-Being, 4, 505-524. https://doi.org/ $10.1007 /$ s42413-020-00087-2

This Article is brought to you for free and open access by the Psychology at Chapman University Digital Commons. It has been accepted for inclusion in Psychology Faculty Articles and Research by an authorized administrator of Chapman University Digital Commons. For more information, please contact laughtin@chapman.edu. 
Does a Good Advisor a Day Keep the Doctor Away? How Advisor-Advisee Relationships are Associated with Psychological and Physical Well-Being among Graduate Students

\section{Comments}

This is a pre-copy-editing, author-produced PDF of an article accepted for publication in International Journal of Community Well-Being, volume 4, in 2020 following peer review. The final publication may differ and is available at Springer via https://doi.org/10.1007/s42413-020-00087-2.

A free-to-read copy of the final published article is available here.

Copyright

Springer 


\title{
Does a Good Advisor a Day Keep the Doctor Away?
}

How Advisor-Advisee Relationships are Associated with Psychological and Physical Well-Being among Graduate Students

\author{
Monica Becerra a, Emily Wong ${ }^{b}$, Brooke N. Jenkins ${ }^{c}$, and Sarah D. Pressman ${ }^{\text {d }}$ \\ ${ }^{a}$ School of Psychological and Behavioral Sciences, Southern Illinois University Carbondale | Carbondale, \\ Il, USA; ${ }^{\mathrm{b}}$ Psychology Department University of California Los Angeles | Los Angeles, CA, USA; ${ }^{\mathrm{C}}$ Crean \\ College of Health and Behavioral Sciences, Chapman University | Orange, CA, USA; ${ }^{\mathrm{d}}$ Department of \\ Psychological Science, University of California Irvine | Irvine, CA, USA
}

Monica Becerra (monica.becerra@siu.edu) is a doctoral candidate in the Counseling Psychology program at Southern Illinois University Carbondale. She focuses on psychosociocultural strength-based research practices on physical and mental health, multicultural competence, multicultural supervision, and experiences of people of color in higher education. Emily Wong (emilyfwong@ucla.edu) is a doctoral student in the Cognitive Psychology program at the University of California, Los Angeles. She is interested in utilizing statistical and computational methods to model moral judgements and decision processes. Dr. Brooke Jenkins (bjenkins@,chapman.edu) is an assistant professor at Chapman University and investigates affect dynamics and health. Dr. Sarah Pressman (pressman@uci.edu) is an associate professor at the University of California, Irvine. She specializes in the interactions between stress, positive psychosocial factors, and physical health.

ORCID iD: 0000-0002-6713-9803

Please email correspondence to: Monica Becerra monica.becerra@siu.edu 
Running head: ADVISORS AND GRADUATE STUDENT WELL-BEING

Does a Good Advisor a Day Keep the Doctor Away?

How Advisor-Advisee Relationships are Associated with Psychological and Physical Well-Being among Graduate Students 


\begin{abstract}
It is well established that graduate students face large amounts of stress during their education. Despite this, little research has focused on factors that can help this high stress population maintain well-being in the face of numerous challenges. One potentially important but neglected probable wellness determinant is the advisor-student relationship. This study explored to what extent advisor and department characteristics related to advisor selection are associated with student well-being, and examined whether a positive advisor-advisee relationship can reduce the negative effects of stress on student well-being. Four hundred and forty-six graduate students from Ph.D. programs across the United States completed an online survey asking advisingrelated questions as well as assessments of stress, physical health, psychological well-being, and demographics. Results indicated that higher faculty advisor satisfaction was associated with reports of higher positive affect, lower negative affect, and better sleep efficiency, but slightly worse health compared to a year prior to survey. Additionally, high quality advisor-student relationships and greater control over switching advisors were associated with less affective disruption under high stress indicating possible stress buffering effects. Together, these results indicate that advisor-advisee relationships in graduate training may be an important future area of intervention and focus for campus well-being.
\end{abstract}

Keywords: faculty advisor-advisee relationships, graduate student health, affect, stress, wellbeing 
Does a Good Advisor a Day Keep the Doctor Away?

How Advisor-Advisee Relationships are Associated with Psychological and Physical Well-Being among Graduate Students

\section{Introduction}

One in three doctoral students experiences distress or is at risk of developing a mental illness like depression (Levecque et al., 2017) at a higher rate than the general population (Evans et al., 2018; Rummell, 2015). Further, graduate students report regular strain, unhappiness, and insomnia (Levecque et al., 2017) as well as high stress (Yusufov et al., 2019). Given the strong causal ties linking stress to worse health (Cohen et al., 2007; Krantz et al., 2013), this sample may therefore be at high risk for both mental and physical illness (Rummell, 2015) that could interfere with their education and future career. Despite these problems and risks, few studies examine factors that might protect graduate students against the harms of stress. We believe that one neglected, but possibly protective factor is a healthy student-advisor relationship. While many have recognized the role that a good faculty advisor can play in academic success (Noy \& Ray, 2012; Schlosser et al., 2011), how this relationship and advisor-related department features are associated with the psychological and physical well-being of graduate students has gone mostly unexplored.

The limited research on the student-advisor relationship focuses predominantly on advisor attitudes and experiences (e.g., Allen \& Smith, 2008), suggested guidelines or behaviors for effective advising (e.g., Barbuto et al., 2011; Barnett et al., 2006), advising as a means to increase student retention (mostly among undergraduates; e.g., Heisserer \& Parette, 2002; Soria, 2012, Tinto, 1999) and advising relationships being important for professional development (e.g., Schlosser et al., 2011). While these are essential topics, connections between the student- 
advisor relationship and graduate student well-being is also of critical value. The little information we do know in this area comes mostly from online popular media publications and news articles (e.g., Inside Higher Ed, The Atlantic) that highlight topics such as graduate school and its association with student mental health, depression and anxiety, as well as poor advisorgraduate student relationships as a potential source of stress. These all point to the need for examining how advisor-advisee relationships are associated with physical and mental health, however little work directly addresses this question.

\section{Social Relationships, Stress, and Well-Being}

It is well documented that the negative downstream effects of stress can be attenuated through positive social relationships, social integration, and feelings of being socially supported (Ozbay et al., 2007). This concept is described as the Stress-Buffering Hypothesis (Cohen \& Pressman, 2004; Cohen \& Wills, 1985), and theorizes that psychosocial resources (e.g., high quality relationships, feeling supported) decrease the negative impact of stress on well-being. Is it possible then, that a good advisor relationship is a source of support that can help prevent a student's health from deteriorating during the trials and tribulations of doctoral education?

Even without considering stress, the quality and quantity of relationships a person has are strongly tied to their physical, emotional, and psychological health (Prati \& Pietrantoni, 2010). In past reviews, socially integrated individuals lived longer lives, had better health, and were happier versus their isolated counterparts (Holt-Lunstad et al., 2010; Umberson \& Montez, 2010). Furthermore, social relationships are connected to health-benefiting behaviors (e.g., better sleep, exercise, diet; Grandner, 2017; Holt-Lunstad et al., 2010), which may be one reason why the social-health connection is so robust. In addition, simply being part of a social network is tied with better self-care, and higher self-esteem, positive affect, life meaning, and purpose (Cohen, 
2004; Holt-Lunstad et al., 2010; Lyubomirsky et al., 2005), indicating an array of well-being benefits. Poor quality relationships, on the other hand, can be a source of stress (Umberson \& Montez, 2010), and have been consistently associated with impaired physical function, health deterioration, delayed illness recovery, depression and anxiety (Robles \& Kiecolt-Glaser, 2003; Strine et al., 2008).

Following this logic, given how central and important an advisor is in graduate education, the advisor-advisee relationship, may be critical for enduring the stressors of graduate school as well as for overall well-being. Should the student-advisor relationship be full of positive interactions, generativity, and support, a student may experience more positive emotions, better health and health behavior, feel prepared to face the stressors of graduate school, and perhaps even pursue opportunities that foster a sense of purpose (e.g., Feeney \& Collins, 2015). Along these lines, in a correlational study conducted by O'Brien et al. (2012), results indicated that first-year students in a peer-mentoring program who had a good mentoring experience reported less academic stress and less worry about not having a sense of belonging. Unfortunately, it may also be the case that a poor student-advisor relationship can be a source of stress itself. Since the advisor has a great deal of influence and power over the future success of a student, a difficult relationship may serve a double whammy by removing a key source of support for the needs of graduate school, while adding an additional stressor to an already stressful environment.

\section{The Advisor Role}

Almost all doctoral students work closely with a faculty advisor who has a substantial influence on their professional development and serves the essential function of helping to develop doctoral students into self-sufficient scholars (Graham, 2013; Noy \& Ray, 2012). Most students and faculty consider mentoring and advising synonymous, but there are distinctions 
(Rugg \& Petre, 2004). For the purposes of this study, we use the broader term "advisor" to refer to someone who works closely with a graduate student and helps develop them into effective professionals (Barnes \& Austin, 2009). This is because while advisor relationships can range from highly positive to highly negative in quality, mentors are, by definition, positive (Mertz, 2004; Schlosser et al., 2011). When students are paired with a good advisor, we see greater positive student development, student success, and higher retention and academic persistence (Drake, 2011; Pargett, 2011; Pizzolato, 2008). Positive advisor-advisee relationships are also related to professional advancement following graduation (Graham, 2013; Vasquez et al., 2006) and better self-perceptions about academic competence (Curtin et al., 2013). In addition, highquality advisor-advisee relationships account for up to an astounding $93 \%$ of student satisfaction with their college experience (Hale et al., 2009; Pargett, 2011). Conversely, advisors can also exacerbate the negative impact of academic pressures, leading to delayed degree attainment or dropout (Graham, 2013), leaving a multitude of avenues by which this relationship can be associated with additional distress and downstream ill health.

As illustrated above, most advisor-advisee research focuses on academic performance as the outcome. It is also critical, however, to understand the well-being consequences given the current crisis in mental health for graduate students (Evans et al., 2018), as well as because of the known impact of poor health on academic performance (Backels \& Wheeler, 2001; Harper \& Peterson, 2005). One relevant study by Hyun and colleagues (2006) examined graduate student mental health needs and utilization of counseling services in a university setting. The researchers gathered data from a cross-sectional survey administered to full-time graduate students with most representing science and engineering disciplines. The online survey was designed to address graduate student knowledge, need, utilization, and satisfaction with mental health services on 
campus as well as factors that are associated with graduate student health like social support and department climate. Some measures included self-reported mental health needs, functional relationship with advisors, program competitiveness, social support, and utilization of mental health services.

Results indicated that graduate student mental health needs are high and students with more functional advisor relationships (based on an index of satisfaction, direction, \& communication) were more likely to utilize counseling services and report positive well-being (Hyun et al., 2006). The researchers suggested that campus leaders need to examine mental health issues on campus and share strategies between the university and departments to safeguard adequate resources for student mental health as well as department specific peer advisor and mentoring programs to mitigate graduate student isolation. However, there are still many unanswered questions regarding the health and health behavior correlates of the advisoradvisee relationship. For instance, does a graduate student who is more satisfied with the relationship they have with their advisor report better well-being? Would other factors like having control over who to work with as a primary advisor or the amount of contact (e.g., meeting in person or via email correspondence) be associated with a graduate student's wellbeing?

Johnson and Huwe (2002) highlighted the many issues of a dysfunctional graduate student-advisor relationship (e.g., mentor relationship incompetence, neglect, relational conflict, exploitation, etc.) and stated that there is a considerable lack of theory development, research, as well as departmental and individual prevention efforts in this area. The authors added that there is a plethora of research highlighting the (mostly academic) benefits of a substantial graduate student-advisor relationship, but fewer acknowledge the potential consequences of a negative 
graduate student-advisor relationship. The authors stated that the advisor role is a significant one in a graduate student's academic career, but relationships can unfortunately be unhealthy and dysfunctional as defined by: (a) the primary needs of one or both partners are not being met, (b) the long-term costs for one or both partners outweighing the long-term benefits, or (c) one or both partners are suffering distress as a result of being in the relationship. Although the authors mentioned that distress can be a consequence of the unhealthy relationship, what exactly are graduate students experiencing especially in regard to their well-being?

One particular factor mentioned by Johnson and Huwe (2002) as the root of a dysfunctional graduate student-advisor relationship is poor matching. Indeed, when considering the advisor role, we must consider the neglected topic of how these advisors are picked/matched and to what extent students have control and flexibility over their advisor assignment. There are a huge variety of approaches to matching students with advisors, as well as different norms regarding the ability to switch advisors should interests change and/or personal issues arise. Being trapped in a dysfunctional relationship with an advisor can have negative effects on a student's well-being and productivity (Scandura, 1998), thus, being able to easily switch advisors, or even simply having the perception that it is possible may be key to student wellbeing. During stress, time and time again, we see that a perception of control (whether it is real or simply believed) can have objective physiological and mental benefits (Wallston et al., 1987). Thus, knowing that a stressor (i.e., a bad relationship) is potentially modifiable without ruining a graduate student's career may be an important and unstudied stress protective factor.

\section{Well-Being Relevant Factors and Behaviors in Graduate Students}


There are many chronic and acute illnesses associated with long lasting stress (e.g., Cohen et al., 2007), however, in typically young and healthy graduate students, what health and health behaviors might be most affected? One important candidate is sleep, whose efficiency and duration is disrupted even under minor stress (Zawadzki et al., 2013). Poor sleep is closely connected to worsened mental (Pilcher et al., 1997) and physical health (Carroll et al., 2015; Wong et al., 2013; Cohen et al., 2009), weaker academic performance (Gaultney, 2010) as well as general related health problems, even in young college samples (Pressman et al., 2017). Not surprisingly, half of graduate students experience chronic physical health symptoms that worsen with increased workload, but also report feeling unsupported by supervisors and faculty, and not making use of mental health services (Rummell, 2015).

In student samples, medical visits can also be utilized as an indicator of health versus illness (Cross \& Pressman, 2018; Pennebaker et al., 1988), and typically represent acute health conditions common in younger samples (e.g., Yawn et al., 2003). Since most universities have health centers and graduate programs typically guarantee access to these centers, probing students about their use of these medical care facilities can provide an indication of illness load in this sample. Furthermore, as has been done in other studies, it is also important to consider graduate student psychological well-being, as health is best defined in a holistic manner with both negative and positive indicators (World Health Organization, 2019). For example, dispositional positive affect (e.g., how happy someone feels) is an important indicator of psychological well-being, a known stress buffer, and a correlate of future health (e.g., Pressman et al., 2019). Vice versa, negative affect (e.g., anxiety, depression) is related to a host of poor health outcomes (Gross \& John, 2003) and as a result, is important for student quality of life as well as for its health relevance (Lopez \& Denny, 2019). 


\section{The Current Study}

The purpose of this study is to better understand how graduate advisor-graduate student relationships and characteristics are associated with student well-being, as defined by both psychological (e.g., stress, emotion) and physical (e.g., sleep, doctor visits) measures since wellbeing is multifaceted. Our main goal was to examine whether graduate student satisfaction with their advisor and sense of advisor support (e.g., communication level, perceived contact and availability, advisor and program satisfaction) were related to well-being. Next, given that departments vary in how this critical relationship is assigned and degree of student control over this relationship (e.g., Can graduate students switch advisors?), we also explored whether graduate program characteristics pertaining to advisor selection (e.g., how advisors are selected, how much control a student has over switching advisors, etc.) were connected to student wellbeing. We hypothesized that students who are more satisfied with the relationship they have with their advisor will report better physical health; be less likely to seek medical care; have more positive and less negative affect; and report better sleep behaviors. We also hypothesized that students who had flexibility in choosing their primary advisor would experience the same benefits. Finally, given the importance of positive and supportive social relationships in reducing the negative effects of stress (Cohen \& Pressman, 2004; Cohen \& Wills, 1985), we hypothesized stress-buffering effects from having high quality relationships and/or high control over the advisor.

\section{Method}

\section{Participants}

Participants $(\mathrm{N}=446)$ were $34 \%$ male, $64 \%$ female, with the remaining subjects responding with "Other" or selecting not to respond. Subjects' ages ranged from 21 to 62 years 
$(\mathrm{M}=29.02, \mathrm{SD}=6.31)$, and years in graduate school ranged from 1 to $8(\mathrm{M}=2.85, \mathrm{SD}=1.615)$.

Participant race was White (69\%), East Asian (15\%), Black/African American (6\%),

Hispanic/Latina/o (6\%), and Other (4\%). Ninety-one (20.87\%) were first generation college students. Participants reported studying in a variety of programs including Social Sciences (45.7\%), Physical/Natural Sciences (13.5\%), Education (12.1\%), Engineering (8.2\%), Humanities (4.6\%), Pharmacy (3.3\%), Math/Information Sciences (2.9\%), Health Policy/Administration (2.4\%), Nursing (2.2\%), Business (1.5\%), and Other (3.6\%). Most students were in their first (25.7\%) or second (23.2\%) year of graduate school, with numbers in each school year decreasing linearly. All participants had to have an assigned faculty advisor to be eligible for the study. Before recruitment, a power analysis with an alpha of 0.05 was done and revealed that 343 participants would be needed to achieve a power of $80 \%$ to detect a small to medium correlation of 0.15 (Faul et al. 2009; Faul et al. 2007). Ten $\$ 30$ gift certificates were provided to participants as part of a lottery for participating. All research procedures were approved by the Institutional Review Board at the University of California, Irvine.

\section{Instruments}

Advisor-Advisee Characteristics. Advisor satisfaction questions included: "How satisfied are you with your primary academic advisor?" and "How satisfied are you with the contact that you have with your primary advisor?" Questions on satisfaction were answered on a scale from 0 (very unsatisfied) to 100 (very satisfied). Due to the high intercorrelation between these two values $(r=.836, p<0.001)$, scores were averaged together for a single satisfaction score.

For advisor contact, participants were asked: "Approximately, how often do you meet with your advisor one-on-one in person?," "Approximately, how often do you meet with your 
advisor in a small group setting (e.g., lab meeting)?," and "Approximately, how often do you receive emails from your advisor?" Responses were answered on a 8-point scale from "multiple times a day," to "less than once a semester." To ensure an adequate number of observations per category, responses were grouped together into the following categories: very often (at least multiple times a week), often (weekly to biweekly), and seldom (once a month or less) with the often group being used as the comparison group in analyses.

Advisor Assignment Characteristics. Advisor assignment questions included: “How was your PRIMARY academic advisor determined?" "I picked my advisor" was treated as the comparison group versus other options (e.g., department selected, a matching process). Participants were also asked about how much control they had over switching advisors from 0 ("No Control") to 100 ("High Control").

Self-Rated Physical Health. To assess improvement or deterioration of a participant's health in the past year, we used a single item: "Since starting your Ph.D. program, on average, how has your health changed?" with answer options ranging from -100 to +100 ; negative scores represent "gotten worse," zero scores represent "no change" and positive scores represent "gotten better." For the final analyses, health change was grouped as "health gotten worse" (a score below zero) and "health gotten better" (a score above zero) with "no change" (a score of 0 ) being the reference group.

Health Center Visits. Participants reported the number of visits they made to a healthcare clinic due to physical health and mental health concerns, specifically "Approximately, how many times have you visited a health center, doctor, or clinic due to physical health concerns (e.g., chronic illness, physical disease, injury) or because you were feeling ill during the last 12 months?," and "Approximately, how many times have you visited a health center, doctor, 
or clinic due to mental health concerns during the past 12 months (e.g., anxiety, depression, stress)?" Due to non-normally distributed responses, constructs were dichotomized for statistical purposes into 0 [ 2 or fewer visits made in the past year] and 1 [ 3 or more visits made in the past year] for physical health and into 0 [0 visits in the past year] and 1 [ 1 or more visits in the past year] for mental health. Groupings of responses were determined by a median split of the data. The median number of clinic visits for physical health was 2 , and the median number of clinic visits for mental health was 0 .

Affect and Stress. A 25-item modified version of the Profile of Mood States (POMS) was used to assess positive and negative affect (PA and NA respectively; Cohen et al., 2003; Usala \& Hertzog, 1989). Adjectives were rated on a 4-point scale (from $1=$ a little accurate to $4=$ extremely accurate) on how accurately an adjective described how they felt in the past four weeks. In our current study, affect subscales had alpha coefficients of 0.90-0.91. Positive affect was calculated by taking the mean score of nine positive affect items (e.g., happy, at ease, full of pep). Negative affect was calculated by taking the mean score of 16 negative affect items (e.g., hostile, unhappy, fearful, tired). A stress score was also calculated using the same response scale as above based on the items "stressed" and "overwhelmed" (Miller et al., 2004). An aggregate stress score was computed by averaging participants' responses to these two items.

Sleep. A shortened version of the Pittsburgh Sleep Quality Index (PSQI) was used to examine sleep habits over the past four weeks (Buysse et al., 1989). Two components were examined: total sleep and sleep efficiency. Total sleep was calculated by taking the difference between typical bed and wake time, subtracting any time lost due to other factors (e.g., if woke up in the middle of the night, couldn't fall asleep). Efficiency was calculated by dividing total 
sleep (in hours) by the total time spent in bed (time in between reporting going to bed and wake up time).

\section{Procedure}

In order to recruit participants, an email was sent to the department heads or graduate program directors of 237 research universities to provide Ph.D. students information about the study. The list of universities was compiled by doing a general internet search of universities in the United States listed in alphabetical order and then selecting universities across all states that provided doctoral degrees. Schools were selected with the intention of selecting graduate students from various disciplines across both private $35 \%(n=83)$ and public $65 \%(n=154)$ universities. Although recruitment invitations were sent to all 50 states, participants were not asked about their geographical location. In addition, Twitter was used to distribute the online survey link. Interested potential participants were directed to a secure Qualtrics website (www.qualtrics.com) with the survey items. Once participants were screened for eligibility and consented, they were directed to the surveys. Surveys included one reading check question to make sure participants were attending carefully to the questions (all participants used in this study answered this check question correctly). After the participants finished the survey, they were redirected to a different website to provide their email address for the lottery drawing to ensure the anonymity of their answers.

\section{Statistical Analyses}

All analyses were conducted in R Studio (v 1.2.5001). Linear regression and logistic regression analyses were used to examine the associations between satisfaction, frequency of interaction, advisor assignment, health, and affect variables. The main independent variables of interest were the advisor-related questions. Well-being measures (physical, behavioral, and 
psychological) were treated as dependent variables in separate models. Analyses controlled for demographics that have been previously tied to or were hypothesized to be connected to graduate student well-being: sex, year in graduate program, age, race and first-generation student status. As shown in the footnote ${ }^{1}$, first-generation status was not a significant predictor of any outcomes. Race analyses were limited to groups with sufficient sample size for analyses (Black, Asian, White, Other, Multiracial) and dummy coded.

Perceived health change was modelled using ordinal regression, and the number of visits to healthcare clinics were modelled using logistic regression. The number of healthcare clinic visits was not modeled as a Poisson Regression as the data did not satisfy the necessary assumptions. Therefore, the outcome variables, "number of healthcare clinic visits for..." was dichotomized to fit a logistic regression model (see methods for information on dichotomized values).

Assumptions of regression were tested, including constant error variance and normality of error terms. When assumptions were not met, dependent variables were checked for skewness. The following variables had issues of skewness: sleep efficiency, total sleep in hours, and negative affect. Thus, these variables were $\log _{10}$ transformed, and subtracted from specific constants to deal with true zero values (e.g., efficiency was subtracted from 101 and then $\log$ transformed while duration was subtracted from 11 to ensure all values remained positive). After

\footnotetext{
${ }^{1}$ Covariates were picked based on preliminary analyses showing associations between variables and outcomes of interest. Greater age was associated with fewer mental health visits $O R=0.950, p=0.008$ and less sleep, $b=0.003$, $\mathrm{p}=0.017$. Females were more likely to report better health, $O R=1.740, p=0.007$ and were more likely to visit a health care provider (physical health $O R=2.36, p<0.001$, mental health $O R=1.75, p=0.02$ ). Females also reported higher NA, $b=0.143, t(394)=2.055, p=0.041$. Students in later years reported better health, $O R=1.276$, $p<0.001$, but also lower PA, $b=-0.066, p=0.010$. Black students reported less sleep duration than whites, $b=$ $0.083, t(385)=2.151, p=0.032$ and multiracial students reported sleeping less efficiently than whites, $b=$ $0.204, t(383)=2.187, p=0.0293$. Asian students were less likely to have visited a healthcare provider for mental health, $O R=0.485, p=0.044$. Identifying as being the first in one's family to attend college was not associated with any outcome of interest.
} 
these transformations, larger values indicated less sleep efficiency and fewer total hours of sleep, respectively. A $\log _{10}$ transformation was also performed on NA, however, because it was positively skewed and the variable was centered, the Negative Affect score was added to 2 (as the smallest value was -0.09). Finally, to test for stress buffering, we examined all the dependent variables above. Each of the advisor and departmental characteristics were interacted with stress to determine whether these variables buffered against the negative effects of stress on the dependent well-being variables.

\section{Results}

\section{Correlations Between Core Explanatory Variables}

Advisor Characteristics. Frequency of emails, individual and group meetings were all positively correlated with one another as shown in Table 1. However, none were highly correlated enough for there to be issues with multicollinearity.

Department Characteristics. How an individual's advisor was determined was correlated with their ratings of control over switching advisors. Those who had an advisor assigned by the school provided lower ratings of control $(M=50.60)$ as compared to those who chose their advisors $(M=65.92), b=-15.31, t(416)=3.16, p=.002$. Those who were assigned an advisor through a matching process also provided lower ratings of control $(M=57.11)$ as compared to those who chose their advisors, $b=-8.81, t(416)=2.65, p=.009$. Those whose advisors chose them provided lower ratings of control $(M=49.54)$ as compared to those who chose their advisors, $b=-16.38, t(416)=3.19, p=.002$. Lastly, those who selected "Other" did not provide significantly lower ratings of control as compared to those who chose their advisors, $b=-12.35, t(416)=1.89, p=.059$.

\section{Associations Between Advisor-Advisee Characteristics and Well-being}


Satisfaction with Advisor. Subjects, on average, were fairly satisfied with their graduate advisors $(M=80.14, S D=22.99$ out of 100$)$. Results indicated that students who were more satisfied with their advisor were less likely to make frequent visits to the healthcare clinic for mental and/or health concerns (mental health: $O R=0.971, p<0.001$, physical health: $O R=$ $.0983, p<0.001$ (see Table 2). Based on these results, for instance, participants in the bottom $10 \%$ of advisor satisfaction were predicted to have a $76 \%$ chance of visiting a healthcare visit for mental health concerns, while those in the top $10 \%$ of satisfaction had a $41 \%$ chance. Similarly, participants who were less satisfied with their advisors were predicted to have nearly a $62 \%$ chance of visiting a healthcare clinic for physical health concerns, while those who were more satisfied had a 39\% chance. "Low" and "high" satisfaction were qualified as the bottom and top $10 \%$ due to a left skew in satisfaction. That said, satisfied students were slightly less likely to report better health, $O R=0.989, p=0.036$. Greater advisor satisfaction was also associated with slightly higher PA, $b=0.009, t(379)=4.573, p<0.001$, and lower NA, $b=-0.002, t(379)=$ 5.655, $p<0.001$ (see Table 2). Finally, satisfied participants slept more efficiently, $b=-0.002, t$ $(366)=-1.981 p=0.048$, and for more minutes, $b=-0.001, t(370)=-1.965, p=0.050($ see Table 2).

One-on-one Meetings with Advisor. Students who met with their advisors once a month or less experienced slightly more PA than those with more frequent meetings, $b=0.248, t(379)$ $=2.232, p=0.026$, and were less likely to have made a healthcare visit for mental health, $O R=$ $0.441, p=0.013$. One-on-one meetings with one's advisor were not associated with any other outcome.

Group Meetings. How often students met with their advisors in a group setting was not associated with well-being outcomes. 
Email Frequency. How often students received emails from their advisors was not associated with well-being outcomes.

\section{Associations between Advisor Assignment Characteristics and Well-being}

How Advisors are Initially Assigned. Individuals who had an advisor assigned to them by the program were less likely than students who chose their advisors to report better health, $O R$ $=0.469, p=0.045$, but had no other differences in outcomes.

Control Over Switching Advisors. Students who reported more control over switching their advisor were slightly less likely to report better health, $O R=0.992, \mathrm{p}=0.023$ (see Table 2). This variable, however, was not associated with any other outcome.

\section{Stress Buffering Effects of Advisor and Assignment Characteristics on Well-Being}

Advisor Characteristics. Advisor characteristics were each interacted with stress level to see if these factors buffered against the negative effects of stress on the dependent well-being variables. Among these interactions, only PA and NA showed effects. Specifically, at high stress (top 10\%), participants with lower advisor satisfaction (bottom 10\%) displayed lower PA as compared to those with similar stress but high advisor satisfaction, $b=0.004, t(381)=2.425, p$ $=0.016$ (Figure 1). Similarly, at high stress, lower advisor satisfaction was associated with higher NA as compared to those with similar stress but high advisor satisfaction, $b=-0.0005, t$ $(381)=-2.282, p=0.023$ (Figure 2). Also of note, holding satisfaction constant, the effect of stress was such that greater stress was associated with lower PA, $b=-0.643, t(381)=-4.932, p<$ 0.001 , and higher NA, $b=0.125, t(381)=7.001, \mathrm{p}<0.001$.

Advisor Assignment Characteristics. Department characteristics were also interacted with stress. Results indicated that low control (-1 SD) in being able to switch advisors was associated with a steeper decline in PA as stress increased as compared to those with higher 
perceived control $(+1 \mathrm{SD})$ over making a switch, $b=0.003, t(380)=2.301 p=0.022$ (Figure 3).

Again, holding the amount of control constant, effect of stress such that more stress was associated with less PA, $b=-0.519, t(380)=-6.550, p<0.001$. No other interactions were significant.

\section{Discussion}

This study found that the advisor-advisee relationship is robustly and consistently associated with graduate student well-being. Specifically, Ph.D. students who reported being satisfied with their advisor were less likely to make frequent visits to a healthcare clinic for mental and physical health services, slept better, and reported better psychological well-being (lower NA and higher PA). Further, there was an interaction such that the association between high stress and poorer psychological well-being was buffered by high advisor satisfaction. Our findings mirror previous research demonstrating that higher quality relationships outside of the academic context are connected with better physical and psychological well-being (Cohen, 2004; Hyun et al., 2006; Thoits, 1995, 2011), but are the first to show this connection in advisoradvisee relationships.

Other advisor features (e.g., frequency of meetings and online contact) were less robustly linked with wellness. Extremely frequent (e.g., more than once a week, weekly) meetings were associated with less PA as compared to those who met monthly, but this may be confounded by students who meet more often doing so because there are problems occurring (as compared to students whose work is going well and therefore require less supervision). Along these lines, regular lab meetings were not harmful, and in fact were associated with a reduction in helpseeking for mental health problems, perhaps indicating that it is not frequency of contact that is 
harmful, but that intensive one-on-one contact may be indicative of something else (e.g., the need for micromanaging, solving ongoing research problems, needing a lot of help with work).

In regard to advisor assignment, our results suggest that picking your own advisor (versus having one assigned to you or feeling like you have no control) is tied to higher self-reported health. Nevertheless, there were not significant associations to well-being based on advisor control, but there was when there was more satisfaction with the advisor. That said, there was an interesting interaction whereby at high stress levels, not having the ability to switch advisors if desired was related to lower PA. While advisor changeability on its own was not associated with any benefit, when paired with high stress, it matters. Knowing that you can leave a relationship if necessary may provide a sense of control that is known to have an array of stress and health related benefits (Wallston et al., 1987).

Overall, while our data set is cross-sectional, our results are consistent with the broader social relationship literature and support the idea that high quality relationships buffer against the harmful wellbeing effects of stress (Cohen, 2004; Cohen \& Wills, 1985). It is also in line with the large literature on well-being correlations with positive social relationships (e.g., Gross \& John, 2003), given our findings that high quality advisor-advisee relationships (as measured by satisfaction) are tied to higher positive emotion, and reduced stress and negative emotion. Likely related to these psychological benefits, this satisfaction was also associated with better sleep quality and efficiency. Sleep is especially critical in a student's life given that on its own it is tied to physiological and health consequences (Cohen et al., 2009), as well as educational consequences (Gaultney, 2010). This provides one plausible pathway to future health concerns and academic stress-inducing problems. Along these lines, advisor satisfaction was also related to a reduced need to seek out frequent mental and physical health assistance at care facilities. 
Thus, it may be that like other research on the robust health consequences of social relationships (e.g., Holt-Lunstad et al., 2010), that this central relationship in a graduate student's life can have important downstream health consequences. Further longitudinal studies and studies with objective health markers are necessary to unpack this possibility.

There were also a few counterintuitive findings. For instance, students who seldom met with their advisors one-on-one were less likely to report visiting a healthcare clinic for mental health concerns and reported higher PA. One possible explanation may be that struggling students need to have more frequent meetings to discuss and address such struggles. Students who have gained some independence and who are successfully making progress on their projects are indeed likely to be in better spirits and require less frequent advisor assistance. In addition, frequent meetings, especially if the advisor relationship is strained or stress-inducing, can be a source of stress in itself.

\section{Limitations}

This work has strengths and limitations that should be considered. The largest limitation is that the data is cross-sectional, therefore we cannot determine directionality. Based on extensive experimental and prospective longitudinal work indicating downstream effects of social relationships on well-being, we hypothesize that it is the relationship characteristics that lead to the well-being outcomes. That said, based on our study design, it is equally possible that high student depression, illness, and stress leads to a more strained and less satisfying advisoradvisee relationship. At the same time, this direction is not feasible with some of the other variables that are more objective and not alterable by the student (e.g., whether or not a student can switch advisors, how the advisor match is done by the department). Another weakness is that due to the on-line methodology, we had to rely on self-report. Future studies should consider 
objective health, behavioral, and physiological measurements as well as observer evaluations of advisor-advisee relationships (e.g., by graduate program coordinators or the faculty advisor). Related to this point, we did not study advisors in this study. Bad quality relationships are harmful to everyone, and university faculty are no exception. Given observed high levels of stress and burnout in professors (Lackritz, 2004), future work on the association between negative advisee relationships or problematic students and faculty well-being should also be considered.

Although our study did not directly test how the advisor-advisee relationship moderated the effects of stress on health outcomes, future longitudinal studies can perhaps implement interventions that are meant to improve the advisor-advisee relationship and test its direct effects. Finally, because we did not collect data on the anticipated year or graduation or the mean time to degree for each individual, we were unable to look at possible interesting interactions and effects of these variables on student well-being and the advisor-advisee relationship. Future studies should also consider how the impact of certain factors, such as frequency and content of advisor consultations, changes over time (especially in the context of time to graduation), and how these factors relate to well-being. Despite these limitations, this study does point to the importance of a neglected topic that may have important implications for student health and university community well-being more broadly.

\section{Conclusion}

Professors are not typically trained to foster healthy relationships with their advisees, nor are students taught important skills on how to maintain or promote the quality of their advisor relationship (or what to do if it has to end). At minimum, universities should be required to have guidelines of what an advisor's role is, and remediation/grievance programs for professors or 
students with a history of advisee-advisor relationships problems, possibly even some equivalent of couples counseling. While there are many factors critical to an institution's success, graduate student drop out and graduate student ill health is a source of a huge amount of wasted institutional money and faculty effort. Attrition rates for doctoral students has been as high as 50\% (Gilmore et al., 2016) with rates being even higher for students of color in Predominantly White Institutions (McClain \& Perry, 2017). Pairing past work that shows that inadequate advisement (Chrzanowski \& Poudyal, 2019) and poor advisor-advisee relationship (Lovitts, 2001) associated with high attrition rates, past work tying future academic success to advisor relationship quality (Pizzolato, 2008; Schlosser et al., 2011), and now this study's findings on the well-being correlates of this relationship, it would behoove universities to start thinking carefully about how to foster healthy faculty-graduate student relationships.

While further longitudinal work is needed to flush out the long term effects of this relationship, it is already clear that education experts and psychologists need to work together for a variety of reasons to develop support groups, advisor specific counseling, mentor training programs, and other creative interventions to help improve advisor-graduate student relationships for campus well-being and success. Further, should the reverse directionality argument also be true, that is, that poor student well-being leads to bad relationships with advisors, then it is time to spend more resources on fostering graduate student well-being more seriously. Given the importance of the advisor relationship to future success, it may be that a two-pronged approach is needed, both working to strengthen individual student well-being as well as heading suggestions (e.g., by Johnson and Huwe, 2002), to promote a culture of mentoring and effective conflict resolution. 


\section{References}

Allen, J. M., \& Smith, C. L. (2008). Importance of, responsibility for, and satisfaction with academic advising: A faculty perspective. Journal of College Student Development, 49(5), 397-411.

Backels, K., \& Wheeler, I. (2001). Faculty perceptions of mental health issues among college students. Journal of College Student Development, 42(2), 173-86.

Barbuto, J. E., Story, J. S., Fritz, S. M., \& Schinstock, J. L. (2011). Full range advising: Transforming the advisor-advisee experience. Journal of College Student Development, 52(6), 656-670. https://doi.org/10.1353/csd.2011.0079

Barnes, B. J., \& Austin, A. E. (2009). The role of doctoral advisors: A look at advising from the advisor's perspective. Innovative Higher Education, 33(5), 297-315.

Barnett, S., Roach, S., \& Smith, M. (2006). Microskills: Advisor behaviors that improve communication with advisees. NACADA Journal, 26(1), 6-12.

Buysse, D. J., Reynolds III, C. F., Monk, T. H., Berman, S. R., \& Kupfer, D. J. (1989). The Pittsburgh Sleep Quality Index: A new instrument for psychiatric practice and research. Psychiatry Research, 28(2), 193-213.

Carroll, J. E., Irwin, M. R., Merkin, S. S., \& Seeman, T. E. (2015). Sleep and multisystem biological risk: A population-based study. Plos ONE, 10(2), 1-15.

Chrzanowski, S. M., \& Poudyal, R. (2019). Attrition in graduate school versus other health professional programs: Etiologies and solutions. Medical Science Educator, 29(1), 329331.

Cohen, S. (2004). Social relationships and health. American psychologist, 59(8), 676-684. 
Cohen, S., Doyle, W. J., Turner, R. B., Alper, C. M., \& Skoner, D. P. (2003). Emotional style and susceptibility to the common cold. Psychosomatic Medicine, 65, 652-657.

Cohen, S., Janicki-Deverts, D., \& Miller, G. E. (2007). Psychological stress and disease. Jama, 298(14), 1685-1687.

Cohen, S., Doyle, W. J., Alper, C. M., Janicki-Deverts, D., \& Turner, R. B. (2009). Sleep habits and susceptibility to the common cold. Archives of Internal Medicine, 169(1), 62-67.

Cohen, S., \& Pressman, S. (2004). The stress-buffering hypothesis. In N. Anderson (Ed.), Encyclopedia of health and behavior (pp. 780 782). Thousand Oaks, CA: Sage Publications.

Cohen, S., \& Wills, T. A. (1985). Stress, social support, and the buffering hypothesis. Psychological Bulletin, 98(2), 310-357.

Cross, M. P., \& Pressman, S. D. (2018). Say cheese? The connections between positive facial expressions in student identification photographs and health care seeking behavior. Journal of Health Psychology, 1359105318790066.

Curtin, N., Stewart, A. J., \& Ostrove, J. M. (2013). Fostering academic self-concept: Advisor support and sense of belonging among international and domestic graduate students. American Educational Research Journal, 50(1), 108-137.

Drake, J. K. (2011). The role of academic advising in student retention and persistence. About Campus, 16(3), 8-12.

Evans, T. M., Bira, L., Gastelum, J. B., Weiss, L. T., \& Vanderford, N. L. (2018). Evidence for a mental health crisis in graduate education. Nature Biotechnology, 36(3), 282. 
Faul, F., Erdfelder, E., Buchner, A., \& Lang, A. G. (2009). Statistical power analyses using G* Power 3.1: Tests for correlation and regression analyses. Behavior Research Methods, 41(4), 1149-1160.

Faul, F., Erdfelder, E., Lang, A. G., \& Buchner, A. (2007). G* Power 3: A flexible statistical power analysis program for the social, behavioral, and biomedical sciences. Behavior Research Methods, 39(2), 175-191.

Feeney, B. C., \& Collins, N. L. (2015). A new look at social support: A theoretical perspective on thriving through relationships. Personality and Social Psychology Review, 19(2), 113147.

Gaultney, J. F. (2010). The prevalence of sleep disorders in college students: Impact on academic performance. Journal of American College Health, 59(2), 91-97.

Gilmore, J., Wofford, A. M., \& Maher, M. A. (2016). The flip side of the attrition coin: Faculty perceptions of factors supporting graduate student success. International Journal of Doctoral Studies, 11, 419-439.

Graham, E. (2013). The experiences of minority doctoral students at elite research institutions. New Directions for Higher Education, (163), 77-87.

Grandner, M. A. (2017). Sleep, health, and society. Sleep Medicine Clinics, 12(1), 1-22.

Gross, J. J., \& John, O. P. (2003). Individual differences in two emotion regulation processes: Implications for affect, relationships, and well-being. Journal of Personality and Social Psychology, 85(2), 348.

Hale, M. D., Graham, D. L., Johnson, D. M. (2009). Are students more satisfied with academic advising when there is congruence between current and preferred advising styles? College Student Journal, 43(2). 
Harper, R., \& Peterson, M. (2005). Mental health issues and college students. NACADA Clearinghouse of Academic Advising Resources.

Heisserer, D.L., \& Parette, P. (2002). Advising at-risk students in college and university settings. College Student Journal, 36(1), 69-84

Holt-Lunstad, J., Smith, T. B., \& Layton, J. B. (2010). Social relationships and mortality risk: A meta-analytic review. Plos Medicine, 7(7), 1-20.

Hyun, J. K., Quinn, B. C., Madon, T., \& Lustig, S. (2006). Graduate student mental health: Needs assessment and utilization of counseling services. Journal of College Student Development, 47(3), 247-266.

Johnson, W. B., \& Huwe, J. M. (2002). Toward a typology of mentorship dysfunction in graduate school. Psychotherapy: Theory, Research, Practice, Training, 39(1), 44-55.

Krantz, D. S., Thorn, B., \& Kiecolt-Glaser, J. (2013). How stress affects your health. August 10, 2017, http://www.apa.org/helpcenter/stress.aspx

Lackritz, J. R. (2004). Exploring burnout among university faculty: Incidence, performance, and demographic issues. Teaching and Teacher Education, 20(7), 713-729.

Levecque, K., Anseel, F., De Beuckelaer, A., Van der Heyden, J., \& Gisle, L. (2017). Work organization and mental health problems in Ph.D. students. Research Policy, 46(4), 868879.

Lopez, R. B., \& Denny, B. T. (2019). Negative affect mediates the relationship between use of emotion regulation strategies and general health in college-aged students. Personality and Individual Differences, 151.

Lovitts, B. E. (2001). Leaving the ivory tower: The causes and consequences of departure from doctoral study. New York, NY: Rowman and Littlefield 
Lyubomirsky, S., King, L., \& Diener, E. (2005). The benefits of frequent positive affect: Does happiness lead to success? Psychological Bulletin, 131(6), 803.

McClain, K. S., \& Perry, A. (2017). Where did they go?: Retention rates for students of color at predominantly white institutions. College Student Affairs Leadership, 4(1), 3.

Mertz, N. T. (2004). What's a mentor, anyway? Educational Administration Quarterly, 40, 541560.

Miller, G. E., Cohen, S., Pressman, S., Barkin, A., Rabin, B. S., \& Treanor, J. J. (2004). Psychological stress and antibody response to influenza vaccination: When is the critical period for stress, and how does it get inside the body? Psychosomatic Medicine, 66(2), 215-223.

Noy, S., \& Ray, R. (2012). Graduate students' perceptions of their advisors: Is there systematic disadvantage in mentorship? Journal of Higher Education, 83(6), 876-914.

O'Brien, M., Llamas, M., \& Stevens, E. (2012). Lessons learned from four years of peer mentoring in a tiered group program within education. Journal of the Australia and New Zealand Student Services Association, 40, 7-15.

Ozbay, F., Johnson, D. C., Dimoulas, E., Morgan III, C. A., Charney, D., \& Southwick, S. (2007). Social support and resilience to stress: From neurobiology to clinical practice. Psychiatry (Edgmont), 4(5), 35.

Pargett, K. (2011). The effects of academic advising on college student development in higher education (Unpublished master's thesis). University of Nebraska-Lincoln, Lincoln, NE. http://digitalcommons.unl.edu/cehsedaddiss/81/ 
Pennebaker, J. W., Kiecolt-Glaser, J. K., \& Glaser, R. (1988). Disclosure of traumas and immune function: Health implications for psychotherapy. Journal of Consulting and Clinical Psychology, 56(2), 239.

Pilcher, J. J., Ginter, D. R., \& Sadowsky, B. (1997). Sleep quality versus sleep quantity: Relationships between sleep and measures of health, well-being and sleepiness in college students. Journal of Psychosomatic Research, 42(6), 583-596.

Pizzolato, J. E. (2008). Advisor, teacher, partner: Using the learning partnerships model to reshape academic advising. About Campus, 13(1), 18-25.

Prati, G., \& Pietrantoni, L. (2010). The relation of perceived and received social support to mental health among first responders: A meta-analytic review. Journal of Community Psychology, 38(3), 403-417.

Pressman, S. D., Jenkins, B. N., Kraft-Feil, T. L., Rasmussen, H., \& Scheier, M. F. (2017). The whole is not the sum of its parts: Specific types of positive affect influence sleep differentially. Emotion, 17(5), 778.

Pressman, S. D., Jenkins, B. N., \& Moskowitz, J. T. (2019). Positive affect and health: What do we know and where next should we go? Annual Review of Psychology, 70, 627-650.

Robles, T. F, Kiecolt-Glaser, J.K. (2003). The physiology of marriage: Pathways to health. Physiology and Behavior. 79:409-16.

Rugg, G., \& Petre, M. (2004). The unwritten rules of PhD Research. New York: Open University Press.

Rummell, C. M. (2015). An exploratory study of psychology graduate student workload, health, and program satisfaction. Professional Psychology: Research and Practice, 46(6), 391399. 
Scandura, T. A. (1998). Dysfunctional mentoring relationships and outcomes. Journal of Management, 24(3), 449.

Schlosser, L. Z., Lyons, H. Z., Talleyrand, R. M., Kim, B. S., \& Johnson, W. B. (2011). Advisoradvisee relationships in graduate training programs. Journal of Career Development, 38, $3-18$.

Soria, K. M. (2012). Advising satisfaction: Implications for first-year students' sense of belonging and student retention. Mentor: An Academic Advising Journal, 1.

Strine, T. W., Chapman, D. P., Balluz, L., \& Mokdad, A. H. (2008). Health-related quality of life and health behaviors by social and emotional support. Social Psychiatry \& Psychiatric Epidemiology, 43(2), 151-159.

Thoits, P. A. (1995). Stress, coping, and social support processes: Where are we? What next? Journal of Health and Social Behavior, 35:53-79.

Thoits, P. A. (2011). Mechanisms linking social ties and support to physical and mental health. Journal of Health and Social Behavior, 52(2), 145-161.

Tinto, V. (1999). Taking retention seriously: Rethinking the first year of college. $N A C A D A$ Journal, 19(2), 5-9.

Umberson, D., \& Montez, J. K. (2010). Social relationships and health: A flashpoint for health policy. Journal of Health and Social Behavior, 51(Suppl), S54-S66.

Usala, P. D., \& Hertzog, C. (1989). Measurement of affective states in adults: Evaluation of an adjective rating scale instrument. Research on Aging, 11(4), 403-426.

The Vasquez refernece has been corrected to: Vasquez, M. J., Lott, B., García-Vázquez, E., Grant, S. K., Iwamasa, G. Y., Molina, L. E., ... \& Vestal-Dowdy, E. (2006). Personal 
reflections: Barriers and strategies in increasing diversity in psychology. American Psychologist, 61(2), 157.

Wong, M. L., Lau, E. Y. Y., Wan, J. H. Y., Cheung, S. F., Hui, C. H., \& Mok, D. S. Y. (2013). The interplay between sleep and mood in predicting academic functioning, physical health and psychological health: A longitudinal study. Journal of Psychosomatic Research, 74(4), 271-277.

World Health Organization. (2019). Constitution. https://www.who.int/about/who-weare/constitution

Yawn, B., Goodwin, M. A., Zyzanski, S. J., \& Stange, K. C. (2003). Time use during acute and chronic illness visits to a family physician. Family Practice, 20(4), 474-477.

Yusufov, M., Nicoloro-SantaBarbara, J., Grey, N. E., Moyer, A., \& Lobel, M. (2019). Metaanalytic evaluation of stress reduction interventions for undergraduate and graduate students. International Journal of Stress Management, 26(2), 132.

Zawadzki, M. J., Graham, J. E., \& Gerin, W. (2013). Rumination and anxiety mediate the effect of loneliness on depressed mood and sleep quality in college students. Health Psychology, 32, 212-222. 


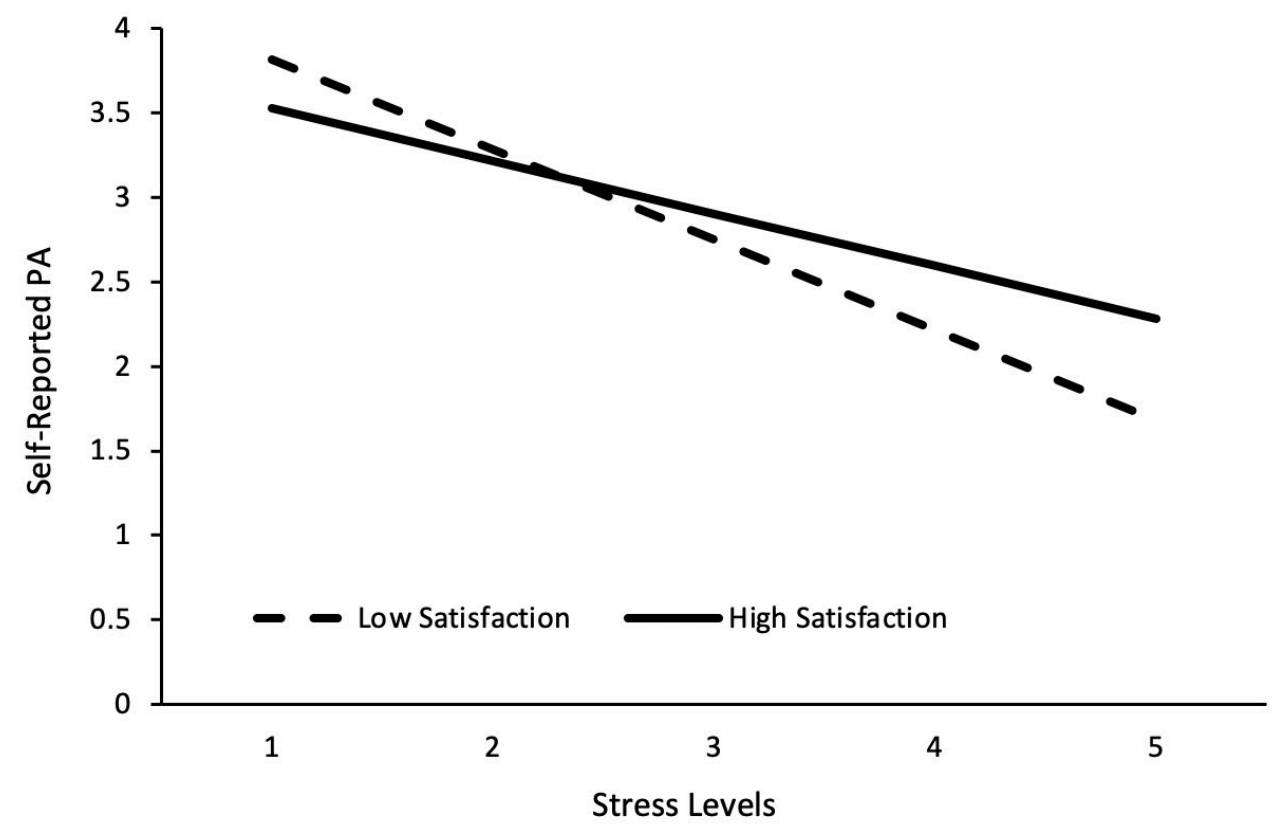

Fig 1 The interaction between advisor satisfaction and stress on positive affect (PA).

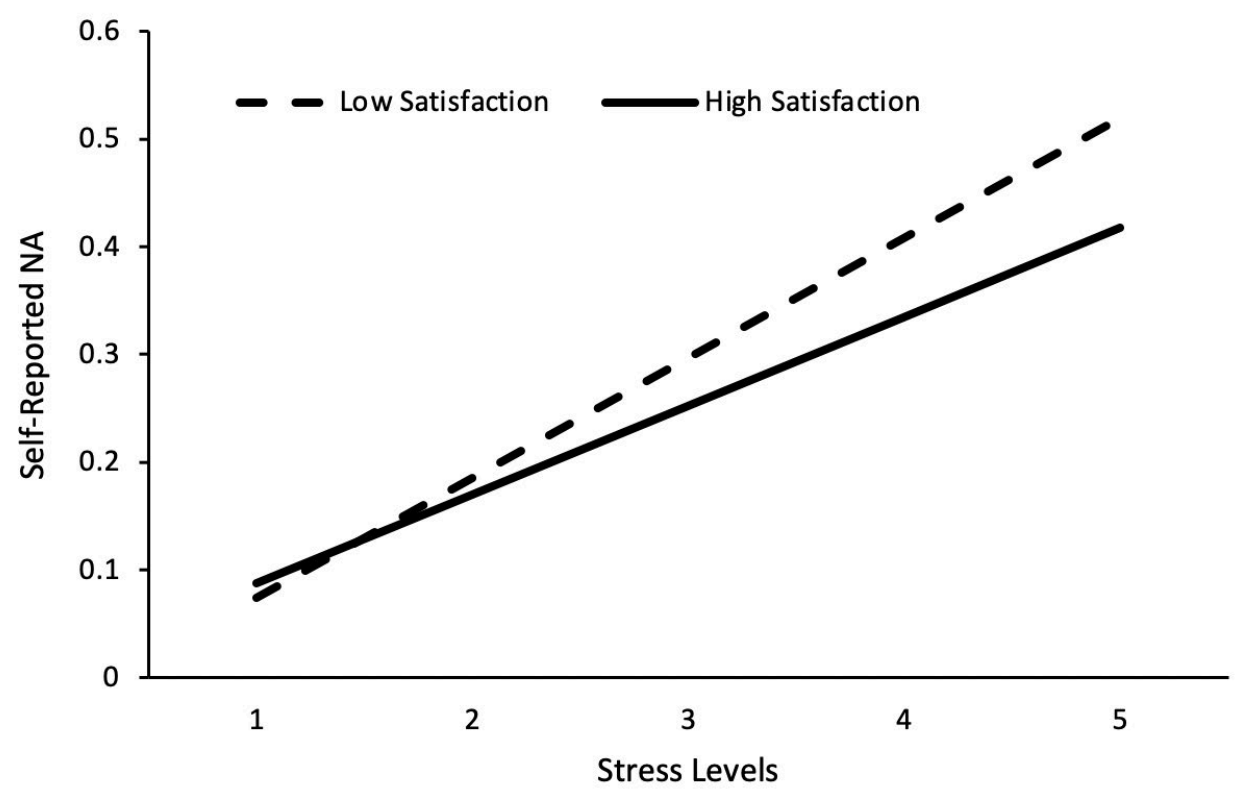

Fig 2 The interaction between advisor satisfaction and stress on negative affect (NA). 


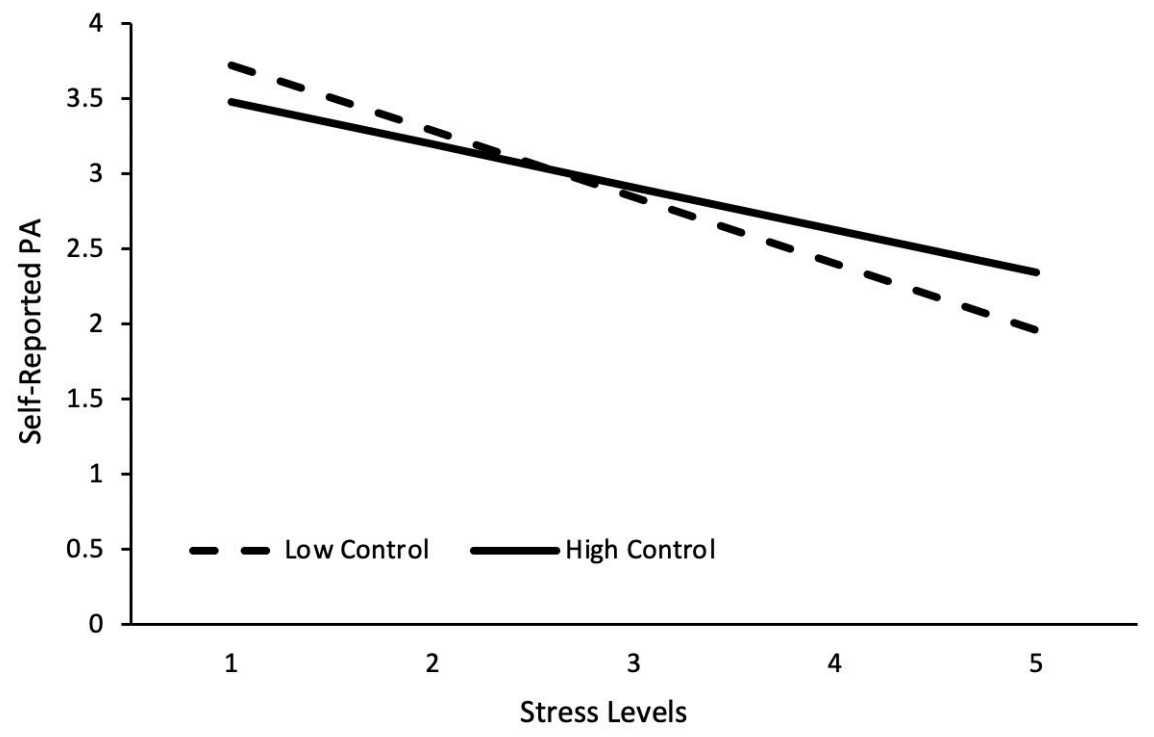

Fig 3 The interaction between control over switching advisors and stress on positive affect (PA). 
Table 1. Advisor Characteristics

\begin{tabular}{|c|c|c|c|c|c|c|c|}
\hline & $\begin{array}{l}\text { Better Health } \\
(\mathrm{OR})\end{array}$ & $\begin{array}{l}\text { Healthcare Visits } \\
\text { for Mental Health } \\
(\mathrm{OR})\end{array}$ & $\begin{array}{l}\text { Healthcare Visits } \\
\text { for Physical } \\
\text { Health } \\
\text { (OR) }\end{array}$ & $\begin{array}{l}\text { PA } \\
\text { (b) }\end{array}$ & $\begin{array}{l}\text { NA } \\
\text { (b) }\end{array}$ & $\begin{array}{l}\text { Sleep } \\
\text { Efficiency } \\
\text { (b) }\end{array}$ & $\begin{array}{l}\text { Sleep Time } \\
\text { (b) }\end{array}$ \\
\hline Satisfaction & $0.989^{*}$ & $0.971 * * *$ & $0.983 * *$ & $0.009^{* * *}$ & $-0.002 * * *$ & $-0.002 *$ & $-0.001 *$ \\
\hline $\begin{array}{l}\text { Email } \\
\text { (seldom) }\end{array}$ & 0.94 & 0.807 & 0.636 & 0.16 & -0.011 & -0.108 & -0.029 \\
\hline $\begin{array}{l}\text { Email } \\
\text { (very } \\
\text { often) }\end{array}$ & 0.875 & 0.96 & 1.269 & 0.102 & -0.002 & 0.053 & -0.002 \\
\hline $\begin{array}{l}\text { Group } \\
\text { Meeting } \\
\text { (seldom) }\end{array}$ & 1.068 & 0.695 & 0.951 & 0.049 & -0.014 & 0.094 & 0.028 \\
\hline $\begin{array}{l}\text { On-on-one } \\
\text { meetings } \\
\text { (seldom) }\end{array}$ & 0.885 & $0.441^{*}$ & 1.066 & $0.248^{*}$ & -0.016 & -0.013 & -0.004 \\
\hline $\begin{array}{l}\text { On-on-one } \\
\text { meetings } \\
\text { (very } \\
\text { often) }\end{array}$ & 0.936 & 0.945 & 1.066 & 0.02 & 0.018 & 0.042 & 0.021 \\
\hline
\end{tabular}




\begin{tabular}{|c|c|c|c|c|c|c|c|}
\hline $\begin{array}{l}\operatorname{Sex}(1= \\
\text { non-male })\end{array}$ & $1.742 *$ & $2.056^{* *}$ & $2.382 * * *$ & -0.174 & $0.034 *$ & 0.046 & -0.016 \\
\hline $\begin{array}{l}\text { Year in } \\
\text { program }\end{array}$ & $1.244 * *$ & 0.973 & 1.048 & -0.045 & -0.002 & -0.014 & -0.008 \\
\hline Age & 1.021 & 0.965 & 1.005 & 0 & -0.001 & 0.006 & $0.003 *$ \\
\hline Black & 0.733 & 2.514 & 1.357 & 0.031 & 0.008 & 0.111 & $0.077^{*}$ \\
\hline Asian & 1.182 & $0.334 * *$ & 1.123 & -0.008 & 0.02 & -0.073 & -0.004 \\
\hline
\end{tabular}

$* p<0.05, * * p<0.01, * * * p<0.001$

Note: Columns with the dependent variables Health Gotten Worse, Health Gotten Better, Healthcare Visits for Mental Health, and Health Care Visits for Physical Health are logistic regressions. The columns with the dependent variables PA, NA, Sleep Efficiency, and Sleep Time are linear regressions. Due to the logarithmic transformation, larger values reflect less sleep efficiency. Lastly, the reference group for the factors email, group meeting and one-on-one meeting is "often" and the reference group for sex is $0=$ male. 
Table 2. Advisor Assignment Characteristics Department

\begin{tabular}{|c|c|c|c|c|c|c|c|}
\hline & $\begin{array}{l}\text { Better Health } \\
\text { OR }\end{array}$ & $\begin{array}{l}\text { Healthcare } \\
\text { Visits for } \\
\text { mental health } \\
\text { OR }\end{array}$ & $\begin{array}{l}\text { Healthcare Visits } \\
\text { for physical health } \\
\text { OR }\end{array}$ & $\begin{array}{l}\text { PA } \\
b\end{array}$ & $\begin{array}{l}\text { NA } \\
b\end{array}$ & $\begin{array}{l}\text { Sleep } \\
\text { Efficiency } \\
\text { b }\end{array}$ & $\begin{array}{l}\text { Sleep Time } \\
\mathrm{b}\end{array}$ \\
\hline Control & $0.992 *$ & 1.002 & 0.994 & 0.002 & 0.000 & 0.000 & 0.000 \\
\hline $\begin{array}{l}\text { Advisor } \\
\text { Assigned } \\
\text { by program } \\
\text { (vs. chosen } \\
\text { by student) }\end{array}$ & $0.469^{*}$ & 0.557 & 0.614 & 0.001 & -0.032 & 0.103 & -0.005 \\
\hline $\begin{array}{l}\text { Matching } \\
\text { process (vs. } \\
\text { chosen by } \\
\text { student) }\end{array}$ & 1.034 & 0.687 & 0.933 & 0.144 & -0.025 & -0.002 & -0.013 \\
\hline $\begin{array}{l}\text { Advisor } \\
\text { picked me } \\
\text { (vs. chosen } \\
\text { by student) }\end{array}$ & 0.909 & 0.505 & 0.56 & 0.078 & -0.027 & -0.099 & -0.025 \\
\hline $\begin{array}{l}\text { Other (vs. } \\
\text { chosen by } \\
\text { student) }\end{array}$ & 1.996 & 1.301 & 1.8 & -0.01 & 0.005 & 0.023 & 0.042 \\
\hline $\begin{array}{l}\operatorname{Sex}(1= \\
\text { non-male })\end{array}$ & $1.759 * *$ & $1.921 * *$ & $2.445 * * *$ & -0.167 & $0.034 *$ & 0.037 & -0.012 \\
\hline $\begin{array}{l}\text { Year in } \\
\text { program }\end{array}$ & 1.267 & 1.005 & 1.065 & $-0.063 *$ & 0.001 & -0.002 & -0.005 \\
\hline
\end{tabular}




\begin{tabular}{llllllll}
\hline Age & 1.047 & 0.961 & 1.011 & 0.008 & -0.001 & 0.002 & $0.003^{*}$ \\
\hline $\begin{array}{l}\text { 1st Gen } \\
\text { Status }\end{array}$ & 1.297 & 1.057 & 0.951 & 0.082 & 0.014 & 0.055 & 0.01 \\
\hline Black & 0.78 & 2.239 & 1.481 & 0.002 & 0.016 & 0.134 & $0.085^{*}$ \\
\hline Asian & 1.288 & $0.399 *$ & 1.223 & -0.055 & 0.022 & -0.076 & 0 \\
\hline Other & 1.101 & 1.065 & 1.879 & -0.057 & 0.029 & 0.101 & 0.026 \\
\hline Multiracial & 1.148 & 1.252 & 1.358 & -0.056 & 0.035 & $0.188^{*}$ & 0.031 \\
\hline
\end{tabular}

$*_{p}<0.05, * * p<0.01, * * * p<0.001$

Note: Columns with the dependent variables Health Gotten Worse, Health Gotten Better, Healthcare Visits for Mental Health, Health Care Visits for Physical Health are logistic regressions. Columns with the dependent variables PA, NA, Sleep Efficiency, and Sleep

Time are linear regressions. 